\title{
BUILT HERITAGE VISUALIZATIONS IN IMMERSIVE ENVIRONMENTS TO SUPPORT SIGNIFICANCE ASSESSMENTS BY MULTIPLE STAKEHOLDERS
}

\author{
P. Jouan, L. Moray, P. Hallot \\ DIVA, Art Archaeology Heritage, University of Liège, 4020 Liège, Belgium (pjouan, p.hallot, loris.moray)@uliege.be
}

Commission II

KEY WORDS: Built Heritage, cultural significance, game engine, point clouds, HBIM, values.

\begin{abstract}
:
In recent years, technological advances in game engines allowed researchers to propose methodological frameworks for integrating digital models of the built heritage in Virtual (VR), Augmented (AR) and Mixed Reality environments. Among other benefits, specific applications have demonstrated the potential of such immersive environments to raise awareness about the significance of historical objects, share associated knowledge and facilitate its collaborative management. Based on the necessity to retrieve information about users' experience, this research considers the potential of such environments to include a broader range of stakeholders in the value assessment process for historical sites and objects and provide more comprehensive representations of their significance for society. This paper proposes implementing a collaborative framework for value assessment in a virtual environment that combines multiple heritage representations to explore this issue. A prototype is further implemented on a practical case study, namely the Collegiate Church of Saint-Jean, located in Liège, Belgium.
\end{abstract}

\section{INTRODUCTION}

Raw point clouds generated by photogrammetric reconstructions and laser scanning surveys provide a first virtual representation of a place of interest and a reliable source for metric data extraction. They also support the reconstruction of other three-dimensional representations of objects in the form of 3D meshes with different levels of accuracy, complexity and information (Banfi, 2021). During the last decades, researchers investigated the use of such 3D reproductions for visualization purposes and to support the organization, storage, and transmission of associated heritage information. In this context, several research projects highlighted the added value of integrating virtual copies of the built heritage in immersive and interactive environments. This approach helps at supporting site operators during maintenance works (Fassi et al., 2016), facilitating the creation of virtual museums (Banfi and Mandelli, 2021), as well as enhancing narratives and evoking the cultural value of heritage places through virtual experiences (Graham et al., 2019).

Besides, cultural significance is now understood as a subjective and fluctuating notion depending on the values associated by society to historical objects at a specific time (Avrami and Mason, 2019). Current approaches for assessing the significance of heritage objects tend to adopt a more inclusive perspective to capture the interpretations of all social groups involved in their preservation and are therefore no longer based on the sole values identified by experts. Considering the immersive, interactive, and accessible aspect of game engines, this paper questions the potential of combining multiple representations of historical places in such environments to enhance the participation of all stakeholders in the value assessment process. The interest of game engines, in this context, is that they allow the development of portable and web applications, accessible to anyone who has access to a computer or smartphone and which do not require extensive computer skills. Furthermore, accessible virtual copies of the built heritage in immersive and interactive environments enhance all stakeholders' participation in the conservation process. Finally, they also could contribute to maintaining a link between society and places of significance in case of temporal or permanent inaccessibility (Hallot et al., 2021).

This paper proposes a prototype of an immersive and interactive environment that allows collecting value judgements associated with multiple users and key metadata about both users and values. The aims are to enable experts to provide more comprehensive representations of historical objects' cultural significance and to confront conservation projects to the previously identified values.

\section{RELATED WORKS}

Andreoli et al. discussed the added value of serious games to support educational activities in the heritage sector (Andreoli et al., 2017). The contribution of Poux et al. demonstrates the benefits of implementing interactive virtual environments to enhance tourists' experiences of cultural heritage sites and improve the transmission of associated knowledge (Poux et al., 2020). Graham et al. proposed a method for 3D modelling of historical buildings and objects to explore the potential of such representations to transmit the cultural values of elements and spaces (Graham et al., 2019). They proposed multiple Level Of Detail, Information and Accuracy (LODIA) to guide the 3D reconstruction of objects or building elements and spaces according to their significance. In addition, Banfi presented a complete methodological framework for integrating HBIM models in VR and AR environments (Banfi, 2021) to enhance accessibility of the information contained such information models by all stakeholders of the conservation project for knowledge to a wider audience.

Beyond the ability of such an environment to enhance knowledge transmission to a broad audience, (Poux et al., 2020) also argued that they allow collecting information, as on the users' behaviour, for instance. This research assumes that virtual reproductions of historical objects in-game engines enable users to collect information about the cultural values associated with them, regardless of their expertise, knowledge, or experience with a site. Such environments also provide a democratic space for non-expert users by enhancing the accessibility of heritage information. Therefore, users can better express their views, interpretations, and value judgments about the built heritage's 
tangible and intangible aspects. Consequently, it contributes to a more inclusive and participatory approach for assessing the significance of a place for all social groups involved.

\section{METHODOLOGY}

To develop a virtual environment that allows users to perform value assessments of the built heritage, we consider the Design Science Research Methodology (DSR) (Lawrence et al., 2010). most suitable as it enables the development of an artefact through the progressive refinement of a prototype and multiple iterations of the process. According to the objectives defined, this first iteration of the DSR process focusses on the development of two aspects (Figure 2) of the prototype; the 3D visualization of heritage sites and the development of an interactive and collaborative framework for assessing their significance.

For the development of the prototype, we opted for Unity 3D. This multi-platform game engine allows the production of games and applications and their integration in immersive environments using AR and VR technologies. (Huang et al., 2019) pointed out that Unity $3 \mathrm{D}$, through several simulation engines, can create realistic effects that enhance intangible aspects of the cultural heritage. Another important argument is that unity offers educational licenses.

While documentation needs can only be precisely determined after defining the cultural significance of historical sites, there is always at least a need to provide a first overview of the place to feed the preliminary studies. Heritage documentation should therefore be considered a process that evolves according to the values associated by society to the tangible and intangible aspects of historical places. The targeted objective of this paper is to permit the integration of various formats of representations. The idea is to support more strategic planning for the documentation of heritage sites by progressively refining the documentation needs, in terms of the level of detail, accuracy and information, based on the values associated with objects. Although the virtual environment should enable the integration of all representations, this paper focuses on three-dimensional virtual copies of the built environment such as point clouds, meshes and object-based $3 \mathrm{~d}$ models.

Besides point clouds obtained with laser scanning survey and photogrammetric reconstructions, the goal is also to integrate 3D meshes with different levels of complexity, taking advantage of existing workflows documented in the literature, like the method proposed in (Graham et al., 2019) and in (Jouan et al., 2021).

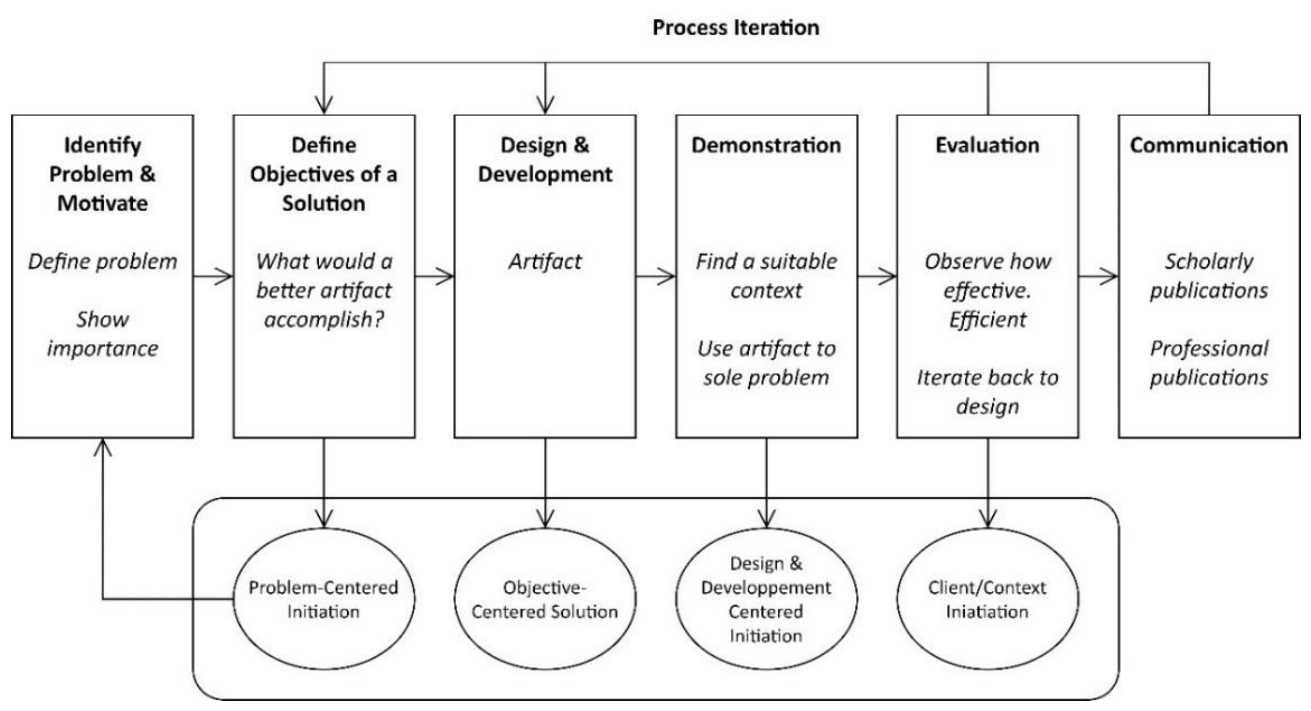

Figure 1. This scheme shows the different steps of the DSR, as presented in (Lawrence et al., 2010)

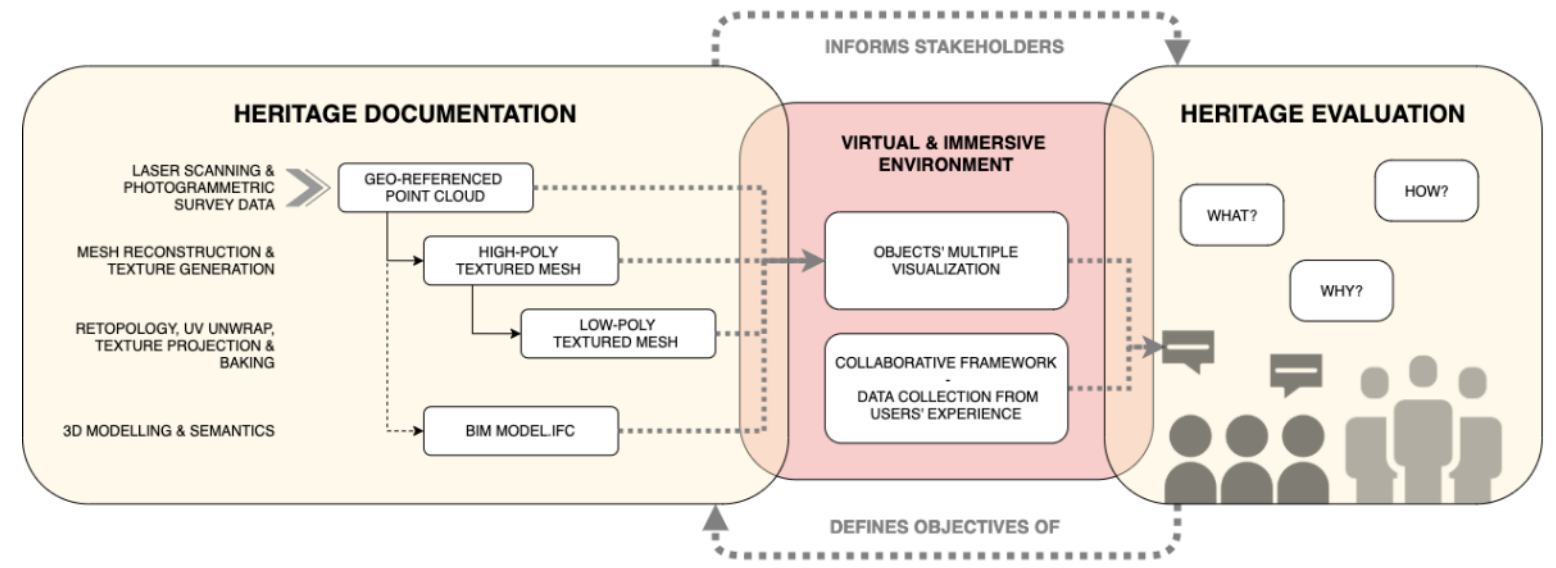

Figure 2. This scheme represents the methodological framework adopted in this research. The multiple visualization and the collaboration framework implemented in game engines support the strategic planning of heritage recording activities as they enhance the iterative process between heritage documentation and evaluation. The objectives of documentation are then gradually specified according to the values associated with heritage places. 
Regarding the collaborative framework, the idea is to implement basic functionalities to enable users to map the values they identified on the different representations proposed. The principles of the framework proposed by Fredheim and Khalaf (Figure 3) for assessing cultural significance (Fredheim and Khalaf, 2016) will guide these developments. This method is implemented in (Houbart and Hallot, 2021) to evaluate digital tools' ability to evocate certain types of values. The same approach is performed by (P. Jouan and Hallot, 2020) to elaborate a data model dedicated to cultural significance data.

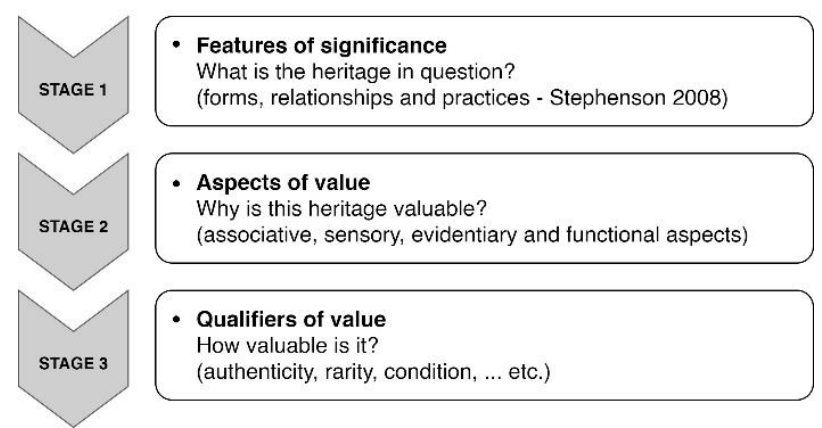

Figure 3. This figure represents the framework elaborated by Fredheim \& Khalaf to evaluate the significance of historical objects.

Finally, Jouan \& Hallot (Pierre Jouan and Hallot, 2020) highlighted that the IFC format structure was suitable for merging semantics associated with heritage objects thanks to the management of multiple scales. The level of data granularity of BIM models also facilitates the implementation of Fredheim and Khalaf's framework as it allows users to associate value judgements to objects considering multiple parts-whole relationships (sites, buildings, spaces, building elements, etc.). However, as temporal reasoning in BIM environments follows a projective logic, it is not adapted to the retrospective logic of conservation projects. If multiple steps along the lifecycle of the case study are to be represented, distinct HBIM models should be produced. Another critical aspect to be developed in future iterations of the DSR process is the integration of users' value judgements, collected in the virtual environment, in a BIM model of a place. Such an approach would enhance the understanding of the object's cultural significance by all users involved in the conservation process.

The prototype will be applied to a practical case study, the Collegiate Church of Saint Jean, located in Liège, in the East of Belgium, evaluating its suitability.

\section{CASE STUDY: THE CLOISTER OF THE COLLEGIATE CHURCH SAINT JOHN THE EVANGELIST OF LIÈGE, BELGIUM}

Among Liege's seven former collegiate churches built along the $10^{\text {th }}$ and $11^{\text {th }}$ centuries, Saint-Jean (Figures $4 \& 5$ ) was commissioned by prince-bishop Notger and built in the island's neighbourhood, outside the first city wall. The original design was based on the Palatine chapel in Aachen, Germany, where Notger received his training. According to (Bolle, 2018), the reference to the design of Charlemagne's sanctuary was overall respected during the reconstruction of the neo-classical building in the late $18^{\text {th }}$ century. The only visible remain of the initial construction is the lower part of the occidental "avant-corps", built in roman style.

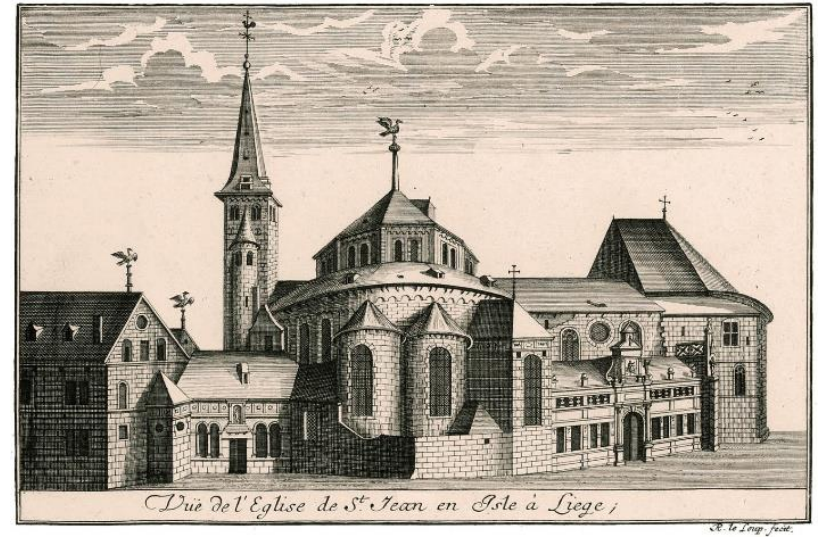

Figure 4. Engraving of Saint-John collegiate church, in 1738 by Remacle Le Loup. Source: Chokier Website: www.chokier.com

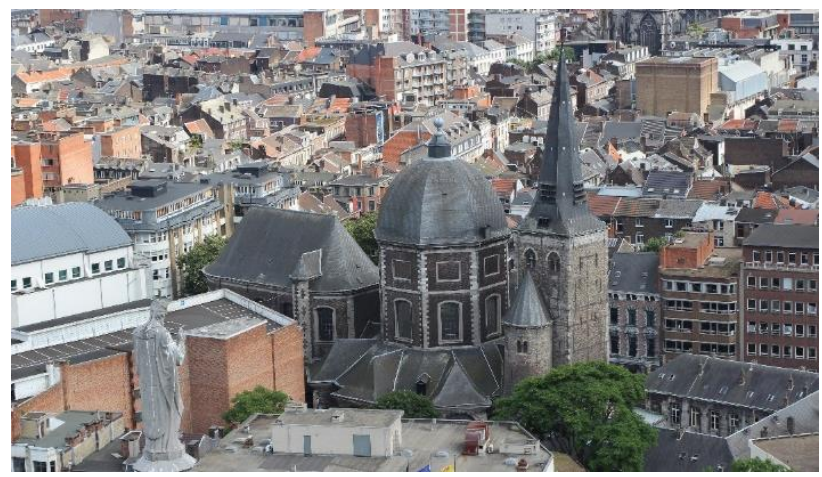

Figure 5. A view towards Saint John Church and cloister from the roof of Saint-Martin Church. Picture taken in 2016, by Cornélis Kill. This picture shows Saint John Church (left), its roman "avant-corps" partly dating back to the $11^{\text {th }}$ century (center) and its cloister (right)

The cloister (Figure $6,7 \& 8$ ) is centred on the plan of the church and located at its western end. Although this configuration has similarities with Aachen Palatine's chapel and its atrium, a recent archaeological study conducted by the Walloon agency to preserve cultural heritage (AWAP) revealed that a cloister with galleries is not contemporary with the construction of Saint John. This investigation intervened before a restoration project of the cloister that will, among other things, integrate ten public housing units in the southern and western wings.

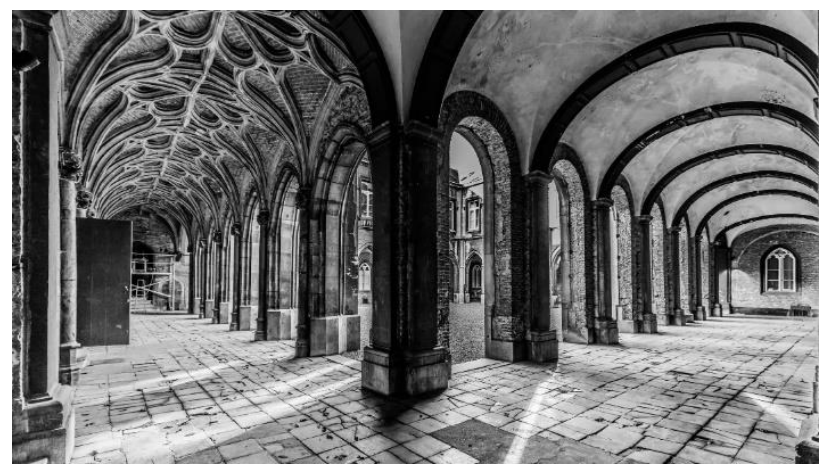

Figure 6. View from the entrance of the cloister, looking towards the southern and eastern wing. Picture taken by James McNellis, 2016. Source: www.flickr.com 


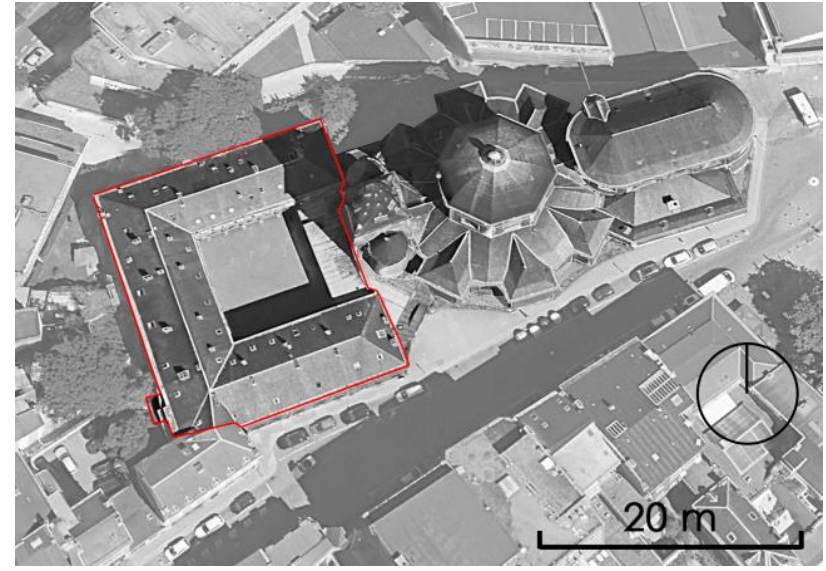

Figure 7. Top view of Saint-Jean Collegiate Church (dark grey) and cloister (highlighted in red). Based on a picture extracted from Google Earth Pro, 2022.

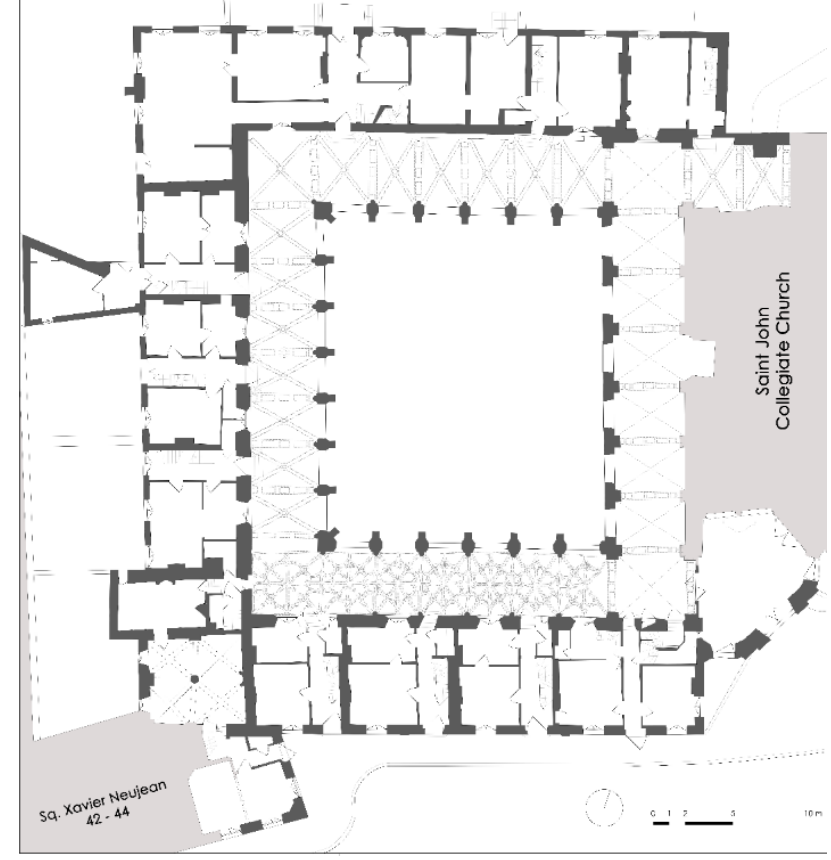

Figure 8. Floor plan of the cloister, ground floor (graphic scale). This document is based on a survey achieved in 2014 by GEOCAD.

In 2021, the site was also invested by the master students of the Faculty of Architecture of the University of Liege in the framework of their project course (Figure 9). The data collected to feed students' architectural and archaeological analysis has been reused in this research. The recording activities aimed at completing the existing documentation about specific zones of the cloister. The survey utilized multiple documentation techniques such as photogrammetry, lasergrammetry and hand measurements. First, laser scanning was used to capture a point cloud of the galleries, the central courtyard, and several interior spaces according to their cultural significance. The scans have been acquired using Leica BLK 360 laserscanner with a resolution of $5 \mathrm{~mm}$ at $10 \mathrm{~m}$. Photogrammetric reconstructions were also performed with varying resolutions according to the objectives pursued. For instance, students target a minimal Ground Sampling Distance of $1 \mathrm{~mm}$ when producing a detailed elevation. Because of time limitations, it was not feasible to survey a network of control points with a total station. Instead, the point cloud obtained with lasergrammetry was used to register all the data in a single environment. A closed-loop through the galleries was achieved to ensure the coherence of the whole model. The registration accuracy was considered sufficient considering the purpose of this research.

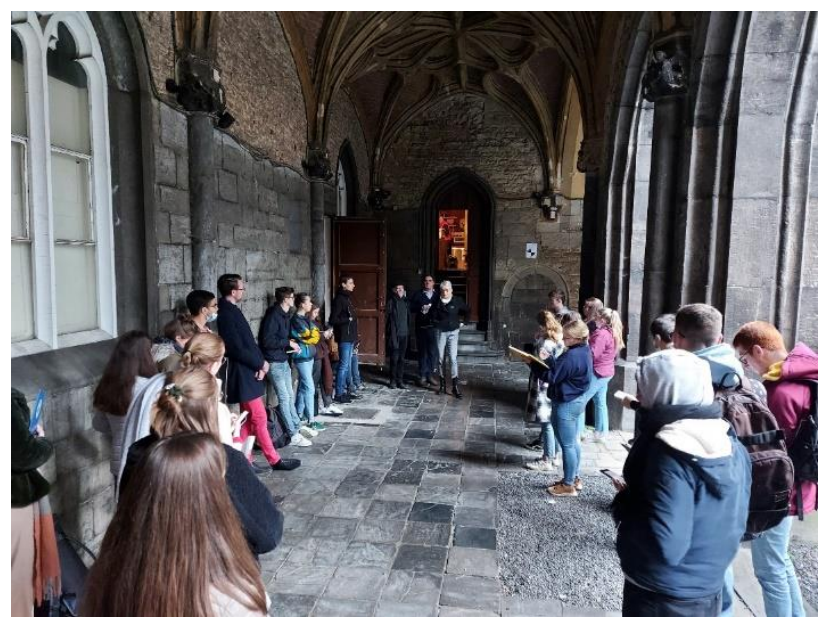

Figure 9. Students at work in the cloister of Saint John collegiate church. Picture by author.

\section{RESULTS}

The prototype was developed with a particular focus on the integration and visualization of multiple representations of objects and the possibility of associating value judgments. The prototype was elaborated in Unity $3 \mathrm{D}$, using the plugin Playmaker for visual programming (version 1.9.1). Figure 10 represent the concept implemented in this paper.

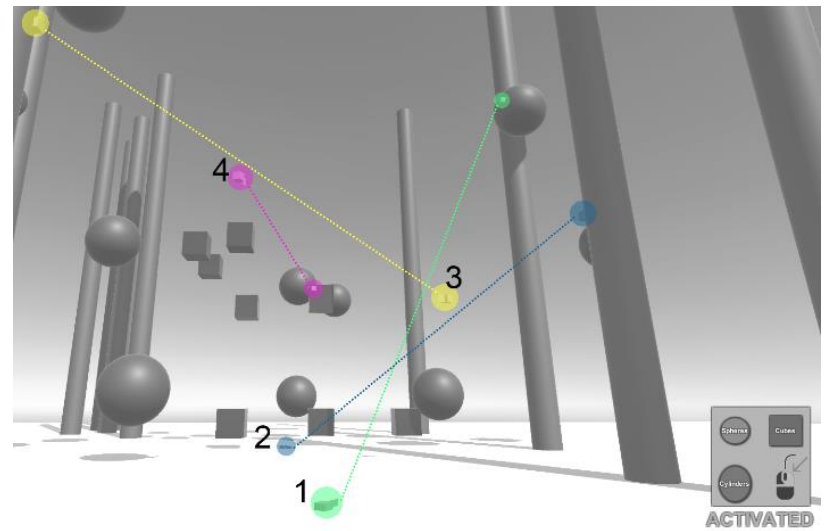

Figure 10 - Conceptual scheme illustrating the geolocation of values on objects in a virtual environment and the relation with users' location when creating the value.

\subsection{Multiple representations and temporalities}

According to the objectives defined in the first sections, the following $3 \mathrm{D}$ productions were successfully imported into the virtual environment. Figure 11 depicts the overall process from data collection to import in Unity 3D. 


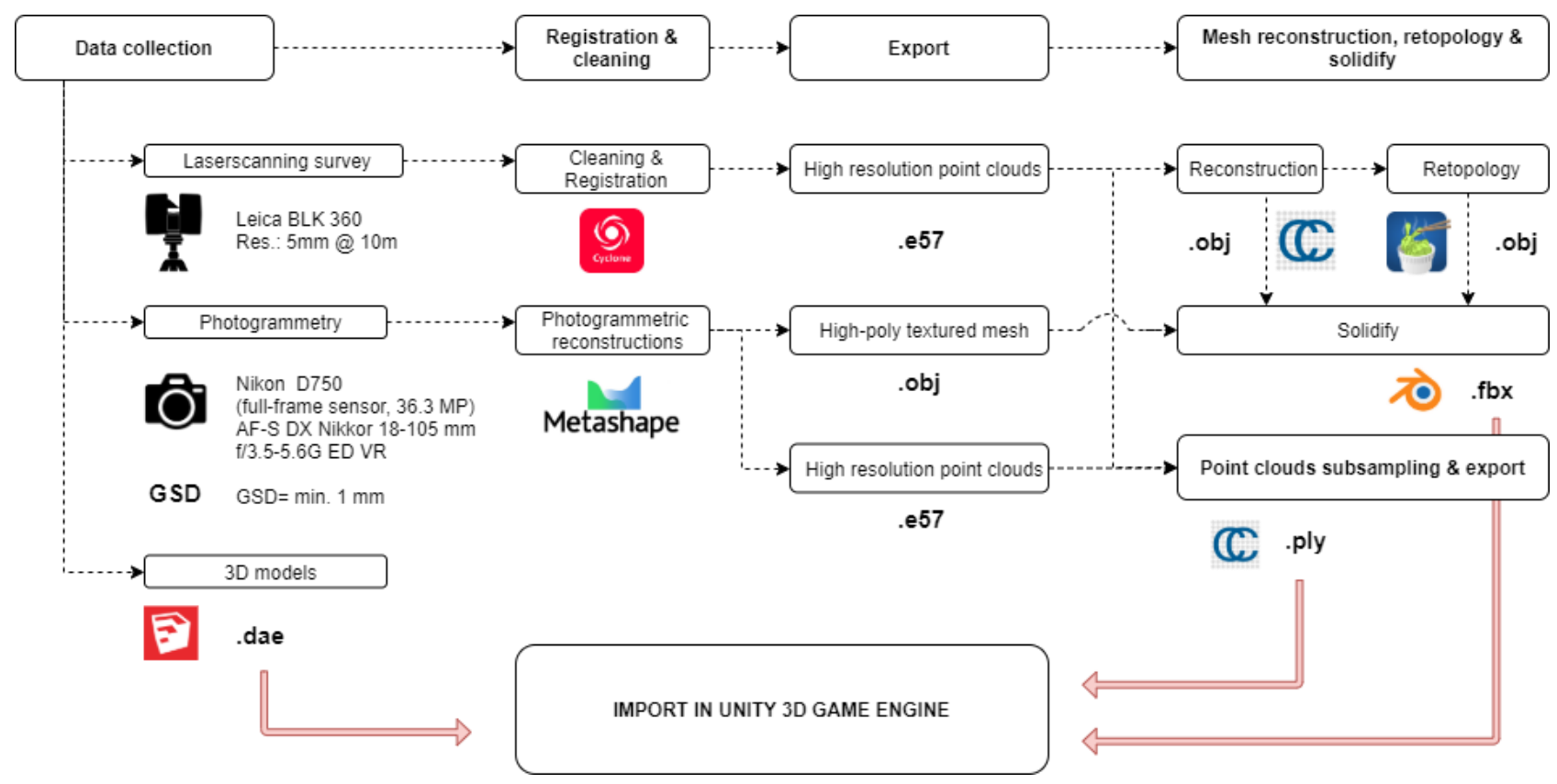

Figure 11 - This figure shows the overall procedure implemented for collecting, processing, and preparing data for import in Unity $3 \mathrm{D}$.

- A point cloud of the cloister with a resolution of $1 \mathrm{~cm} \mathrm{(40}$ million points, attribute: intensity, file size: $680 \mathrm{Mo}$ ) to provide users with an overview of whole site. A low poly mesh with a transparent texture was also added to enable collisions of users' avatar with walls and floors (98.378 faces, file size: $12 \mathrm{Mo}$ ) (Figure 12).

- A high poly-mesh of the cloister (21 million faces, file size: $390 \mathrm{Mo}$ )

- $\quad$ A high-density point cloud (28 million points, attributes: RGB and intensity, file size: $738 \mathrm{Mo}$ ) and a low poly textured mesh ( 2 million faces, file size: $139 \mathrm{Mo})$ of archaeological evidence in the western wing that appear to provide information about the construction of a former refectory. Photogrammetric reconstruction produced these representations in Agisoft Software Metashape (version 1.7.5). The minimum GSD was set at $1 \mathrm{~mm}$ to produce accurate and detailed elevations.

- Additional data has been integrated for these spaces because of the sensory, evidentiary, and functional values associated with the Notger room and the underneath space called "the crypt", located at the intersection of the southern and western wing (Figure 12). First, two 3D models elaborated by the students reconstitute assumptions about previous states of existence of the crypt. Then, the $3 \mathrm{~d}$ model of the project presented by the students working on these two spaces was also integrated. Produced by the students in Trimble Sketchup software, these models were imported in unity using the Collaborative Design Activity (.dae) format. A higher resolution mesh was also integrated for both spaces (Notger: 6 million faces, file size: 132 Mo; Crypt: 14 million faces, file size: $233 \mathrm{Mo}$ ) and divided into multiple game objects due to Unity 3D limitations.

A dedicated menu was developed to allow users to manage the display of the different files according to their specific needs. Several issues were faced at this stage. First, as point clouds format are not directly importable in unity $3 \mathrm{D}$, point clouds were imported using the .ply format. In further steps, the method proposed by (Kharroubi et al., 2019) for classifying and visualizing massive point clouds in the virtual environment will be implemented to enhance visualization. Another solution is to develop the prototype in another game engine that already proposes a plugin for importing and visualizing point cloud data, such as Unreal Engine by Epic Games. Besides, as unity enables the importation of a maximum of 65,000 vertices, large meshes had to be divided into multiple game objects. Meshes were slightly extruded using the solidify modifier in Blender to avoid backface culling issues in unity. However, this solution is not ideal as it generates additional geometry, significantly increases meshes' file size and therefore impact memory consumption when running the application. In the case of meshes that should be seen from one side only, polygons' normal should be correctly oriented. When two-sided meshes are required, normals should be doubled and flipped to avoid culled faces issues in game engines. Finally, to optimize visualization, large meshes should be segmented and imported at multiple LOD using the LOD group component in Unity 3D following, for instance, the approach proposed in (Graham et al., 2019).

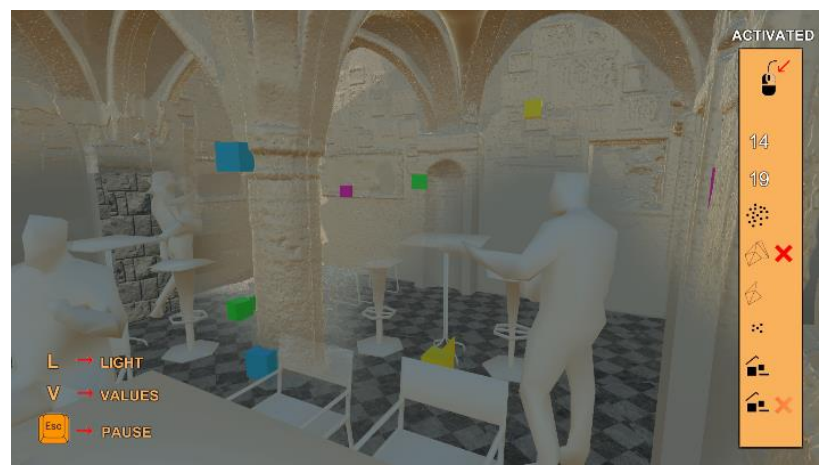

Figure 12. This figure, adapted from screenshots extracted from the virtual environment, shows the overlay of a mesh representing the current state of Notger room with a project proposal. Identified values are also visible to enable users to evaluate the proposal's coherence with the space's cultural significance. 
The integration of projective and retrospective models (Figure 13) shows the potential of such an environment to inform users about the evolution of objects through time and enable the latter to evaluate the adequation of conservation projects with the cultural values identified. Furthermore, such an approach strengthens the link between the value assessment process and the other phases of the conservation process. Finally, it involves a more comprehensive range of stakeholders in the decisionmaking processes, for instance, in evaluating a conservation project proposal.

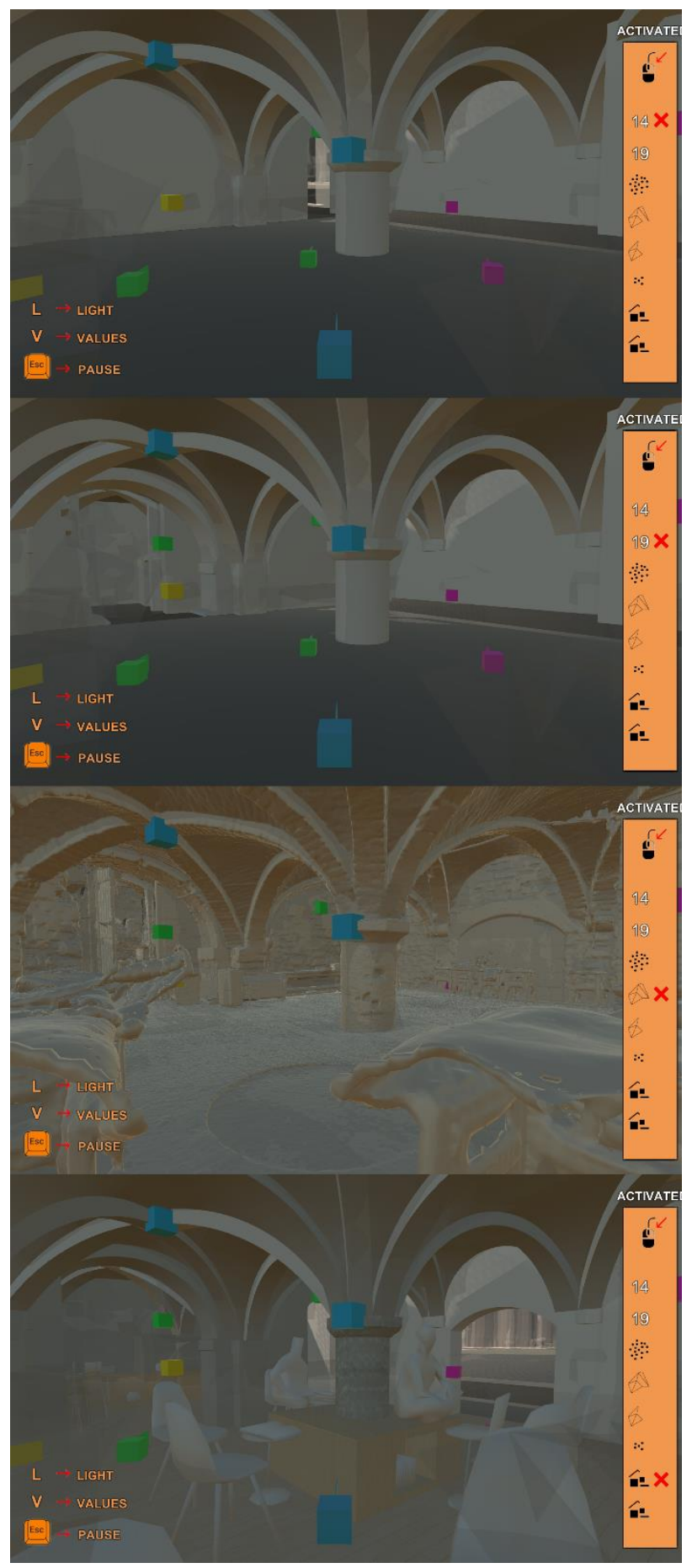

Figure 13. Representation of multiple states of existence of the crypt in the virtual environment. The image successively depicts two reconstitutions of previous states $\left(14^{\text {th }} \& 19^{\text {th }}\right.$ century), the present state and finally, the project.
Although multiple plugins, like the Unity IFC importer or Tridify BIM tools for unity, enable importing IFC models in Unity $3 \mathrm{D}$ while conserving the data structure and all properties and metadata associated with objects, no off-the-shelves solution was found to retrieve the information added by users in the virtual environment and export the enriched HBIM model back in IFC format. Therefore, it was decided to leave the development of this dimension to the next iteration in the elaboration of the prototype.

Finally, two navigation modes were implemented in the prototype. The first-person view allows the complete immersion of users in the site's virtual copy simulates best a visit of the place in the physical realm. On the other hand, free navigation allows considering multiple scales and observing the object from inaccessible locations. A third mode will allow users to switch from perspective to orthographic projection and generate sections. The idea is to offer users the possibility to choose the most suitable navigation mode considering their expertise and experience.

\subsection{Value assessment \& geolocation}

Adopting the principles of the significance assessment framework of Fredheim \& Khalaf (Fredheim and Khalaf, 2016), the prototype allows users to share their interpretations of the built heritage in the virtual environment. To do so, the first step involves the identification of the object to be associated with a new value judgement. Then, by activating the value functionality, users can detect objects faced by the pointer and associate new interpretations. An interesting aspect of this approach lies in both the user's geolocation and interpretation (Figure 14). Indeed, users' location when adding new values is recorded and materialized in space. Combining the data of multiple users and keeping track of their journey would also allow generating heat maps and highlighting important points of observation, as proposed in (Chen et al., 2020). Such data could bring significant inputs to orient conservation projects, particularly regarding the accessibility of spaces with high cultural significance.

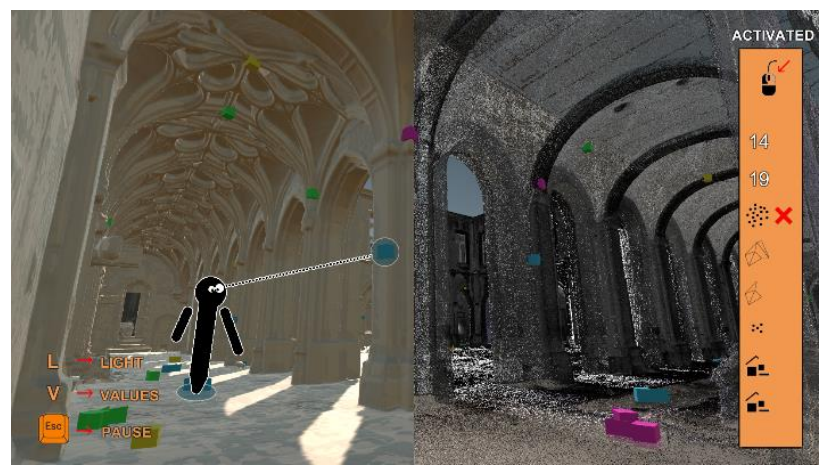

Figure 14. Users can choose the most appropriate representation of a historic site (in this case, a high-poly mesh (left) and dense point cloud (right) to identify further cultural values associated with the place and its constitutive elements. The figures illustrate that both the values and the users' location are registered and materialized in the space.

In a second phase, users must define the type of value that is being added; evidentiary, functional, sensory, or associative. A dialog box also allows users to provide further explanations about the value. In the case of associative aspects of value, they can describe the related tangible or intangible feature(s). Once validated, values are materialized in space on the related object and associated with a colour depending on its type (Figure 15). 


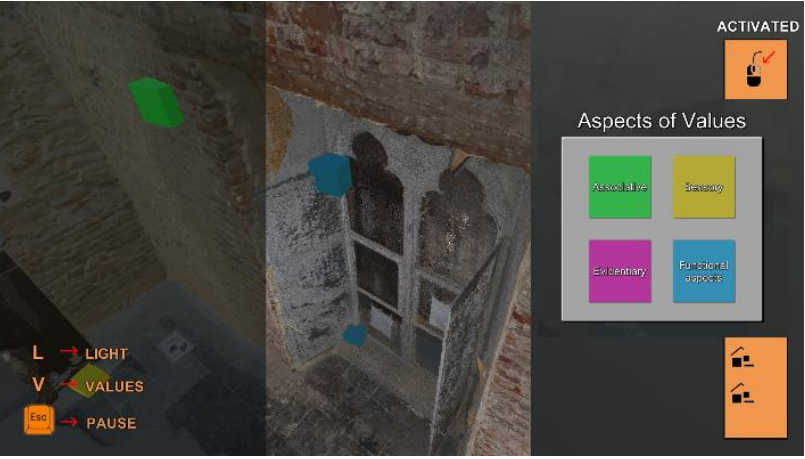

Figure 15. This figure illustrates the possibility of creating new values, defining the related aspect of value, and providing a description. The image also shows the integration of a point cloud and high poly textured mesh generated with photogrammetry.

\subsection{Discussion}

Beyond the implemented features, the developed prototype considers many other research perspectives.

First, as the virtual environment allows to raise awareness about the significance of a place to the broad public, it also allows to capture data about interpretations of multiple stakeholders while recording key information about the identified values (time, geolocation, related objects, value type, description) and the corresponding user (expertise, experience with the site, degree of involvement in the project, age, gender, etc.). Retrieving such data allows multiple representations of cultural significance data, highlighting the values identified by a targeted public or even simply classifying values according to different criteria. This approach would enrich and facilitate the work of experts specialized in assessing the significance of heritage sites and objects. It would provide a more comprehensive view of the whole set of values associated with the built heritage. To do so, tailored data retrieval functionalities should be developed, and the workflow should be applied to multiple case studies to determine the usefulness of the collected metadata in assessing the overall significance of objects.

Besides, retrieving data about users' geolocation and their experience in the Virtual Environment could also provide valuable data to orient conservation projects to a certain extent. Indeed, identifying users' location when identifying new values and creating heat maps reflecting their journey allows highlighting essential points of interest for the perception of specific values. In addition, the need to develop an IFC export plugin for unity $3 \mathrm{D}$ has been discussed in the text to ensure the interoperability of retrieved information from the game environment.

Another important track to be investigated is the possibility to evaluate the coherence of conservation projects with the value judgements associated with features of the built heritage. Indeed, thanks to the geolocation of values, the prototype allows to compare multiple proposals and directly confront these projects to the significance of the place. This topic is particularly interesting as it could considerably strengthen the link between the value assessment and the project and, therefore, the impact of identified value on conservation decisions.

Finally, further research might take advantage of the prototype to identify the most suitable representations for users to identify the different aspects of value associated with objects, depending on the user's expertise and experience. This would progressively enhance users' ability to identify values by proposing key representations tailored to their profile.

\section{CONCLUSIONS}

This paper presented a virtual environment prototype that allows capturing values associated by multiple stakeholders to features of the built heritage. The interest of this research lies in the geolocation of value judgements and the possibilities offered in terms of data retrieval. Beyond the capacity of semantically enriched 3D models of cultural heritage sites to raise awareness about the stakes related to their preservation and inform non expert stakeholders about their history, this paper shows that immersive and interactive virtual environments can also support a more inclusive perspective on the significance assessments of historical objects. Furthermore, the collaborative dimension of the method allows capturing the values associated with a place by multiple stakeholders.

The methodological framework proposed integrates multiple representations of historical objects in an immersive environment. On the one hand, this supports more strategic planning of heritage surveys as it indicates the documentation objectives according to the nature of values associated and the strength of these associations. On the other hand, it allows managing multiple temporalities, either informing users about previous states of existence or enabling users to confront conservation project proposals with the values associated with a place. The integration of cultural significance data in the framework of projects' evaluation and comparison is another added value of this paper. It enhances the synergy between experts involved in different phases of the conservation project. This paper opens many research perspectives. For instance, it provides new means to include the views of non-expert stakeholders in the conservation process. Further research should investigate how to take advantage of such a method, optimize their use, and situate their added value for heritage conservation.

\section{ACKNOWLEDGEMENTS}

The authors wish to thank students for sharing the data of their project work and authorizing their use in this paper's framework. The general point cloud was collected in collaboration with all the students. M.K. Djouadi and B. Lamock achieved the photogrammetric reconstruction of a wall in the western wing. J. Mattart and M. Lemaire achieved the $3 \mathrm{~d}$ models in Notger room and in the "crypt".

\section{REFERENCES}

Andreoli, R., Corolla, A., Faggiano, A., Malandrino, D., Pirozzi, D., Ranaldi, M., Santangelo, G., Scarano, V., 2017. A framework to design, develop, and evaluate immersive and collaborative serious games in cultural heritage. J. Comput. Cult. Herit. 11, 1-22. https://doi.org/10.1145/3064644

Avrami, E., Mason, R., 2019. Mapping the issues of value, in: Avrami, E., Macdonald, S., Mason, R., Myes, D. (Eds.), Values in Heritage Management: Emerging Approaches and Research Directions. The Getty Conservation Institue, Los Angeles, pp. 9-33.

Banfi, F., 2021. The evolution of interactivity, immersion and interoperability in HBIM: Digital model uses, VR and AR for built cultural heritage. ISPRS Int. J. Geo-Information 10. https://doi.org/10.3390/ijgi10100685 
Banfi, F., Mandelli, A., 2021. INTERACTIVE VIRTUAL OBJECTS (IVOs) FOR NEXT GENERATION OF VIRTUAL MUSEUMS: $\quad$ FROM STATIC TEXTURED PHOTOGRAMMETRIC AND HBIM MODELS TO XR OBJECTS FOR VR-AR ENABLED GAMING EXPERIENCES. Int. Arch. Photogramm. Remote Sens. Spat. Inf. Sci. XLVI-M-1-2，47-54. https://doi.org/10.5194/isprsarchives-xlvi-m-1-2021-47-2021

Bolle, C., 2018. Liège/Liège: évolution des bâtiments claustraux de la collégiale Saint-Jean-en- l'isle 125-131.

Chen, G., Shi, J., Xia, Y., Furuya, K., 2020. The sustainable development of urban cultural heritage gardens based on tourists' perception: A case study of Tokyo's cultural heritage gardens. Sustain. 12. https://doi.org/10.3390/SU12166315

Fassi, F., Mandelli, A., Teruggi, S., Rechichi, F., Fiorillo, F., Achille, C., 2016. VR for Cultural Heritage: A VR-WEB-BIM for the Future Maintenance of Milan's Cathedral, in: Paolis, L.T. De, Mongeli, A. (Eds.), Augmented Reality, Virtual Reality, and Computer Graphics. Springer International Publishing Switzerland, pp. 139-157. https://doi.org/10.1007/978-3-319-40651-0

Fredheim, L.H., Khalaf, M., 2016. The significance of values: heritage value typologies re-examined. Int. J. Herit. Stud. 22, 466-481. https://doi.org/10.1080/13527258.2016.1171247 To Graham, K., Chow, L., Fai, S., 2019. From BIM to VR: Defining a level of detail to guide virtual reality narratives. J. Inf. Technol. Constr. 24, 553-568. https://doi.org/10.36680/J.ITCON.2019.031

Hallot, P., Lambert, M., Jouan, P., 2021. Communication tools for inaccessible places of significance. Int. Arch. Photogramm. Remote Sens. Spat. Inf. Sci. - ISPRS Arch. 46, 293-299. https://doi.org/10.5194/isprs-Archives-XLVI-M-1-2021-2932021

Houbart, C., Hallot, P., 2021. May digital tools help preserve the material and evocative value of fragments? The case of Victor Horta' s Hôtel Aubecq in Brussels, in: Das Fragment Im Digitalen Zeitalter. Möglichkeiten Und Grenzen Neuer Techniken in Der Restaurierung. Proceedings of the Interdisciplinary Conference of the HAWK University of Applied Sciences and Arts Hildesheim/Holzminden/Göttingen in Cooperation with IC. pp. 107-123.

Huang, W., Xiang, H., Li, S., 2019. The application of augmented reality and unity $3 \mathrm{D}$ in interaction with intangible cultural heritage. Evol. Intell. https://doi.org/10.1007/s12065019-00314-6

Jouan, P., Hallot, P., 2020. Digital Twin : Research Framework to Support Preventive Conservation Policies. Int. J. GeoInformation 9.

Jouan, Pierre, Hallot, P., 2020. Digital twin: Research framework to support preventive conservation policies. ISPRS Int. J. Geo-Information 9. https://doi.org/10.3390/ijgi9040228

Jouan, P., Sadzot, P., Laboury, D., Hallot, P., 2021. EXPERIENCE AND ATMOSPHERE OF THE BUILT HERITAGE IN DIGITAL ENVIRONMENT. Int. Arch. Photogramm. Remote Sens. Spat. Inf. Sci. XLVI, 329-337.
Kharroubi, A., Haiji, R., Billen, R., Poux, F., 2019. Classification and integration of massive $3 \mathrm{D}$ points clouds in a virtual reality (VR) environment. Int. Arch. Photogramm. Remote Sens. Spat. Inf. Sci. - ISPRS Arch. 42, 165-171. https://doi.org/10.5194/isprs-archives-XLII-2-W17-165-2019

Lawrence, C., Tuunanen, T., Myers, M.D., 2010. Extending Design Science Research Methodology for a Multicultural World Extending Design Science Research Methodology for a Multicultural World, in: Pries-Heje;, J., Venable;, J., Bunker;, D., Russo;, N.L., DeGross., J.I. (Eds.), Human Benefit through the Diffusion of Information Systems Design Science Research. TDIT 2010. IFIP Advances in Information and Communication Technology. Springer, Berlin, Heidelberg, pp. 111-126. https://doi.org/10.1007/978-3-642-12113-5

Poux, F., Valembois, Q., Mattes, C., Kobbelt, L., Billen, R., 2020. Initial user-centered design of a virtual reality heritage system: Applications for digital tourism. Remote Sens. 12. https://doi.org/10.3390/RS12162583 